We have presented the Graphical Abstract text and image for your article below. This brief summary of your work will appear in the contents pages of the issue in which your article appears.

Q3<smiles>C#[C+][P+]=S(=O)(N=c1[nH]ccs1)c1ccc([NH3+])cc1</smiles>

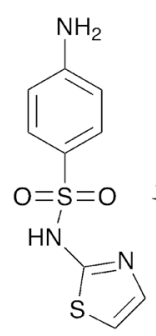

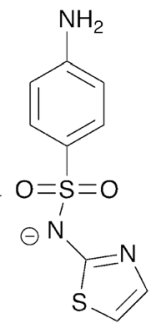

Structural motifs in salts of sulfathiazole: implications for design of salt forms in pharmaceuticals APIs

Colin C. Seaton, * Rayan R. Thomas, Eman A. A. Essifaow, Elisa Nauha, Tasnim Munshi and Ian J. Scowen*

The creation of salts is a frequently used approach for the modification of physicochemical properties of an active pharmaceutical ingredient.

Please check this proof carefully. Our staff will not read it in detail after you have returned it.

Proof corrections must be returned as a single set of corrections, approved by all co-authors. No further corrections can be made after you have submitted your proof corrections as we will publish your article online as soon as possible after they are received.

Please ensure that:

- The spelling and format of all author names and affiliations are checked carefully. Names will be indexed and cited as shown on the proof, so these must be correct.

- Any funding bodies have been acknowledged appropriately.

- All of the editor's queries are answered.

- Any necessary attachments, such as updated images or ESI files, are provided.

Translation errors between word-processor files and typesetting systems can occur so the whole proof needs to be read. Please pay particular attention to: tables; equations; numerical data; figures and graphics; and references.

Please send your corrections preferably as a copy of the proof PDF with electronic notes attached or alternatively as a list of corrections - do not change the text within the PDF file or send a revised manuscript. Corrections at this stage should be minor and not involve extensive changes.

Please return your final corrections, where possible within 48 hours of receipt, by e-mail to: crystengcommarsc.org. If you require more time, please notify us by email. 


\section{Funder information}

Providing accurate funding information will enable us to help you comply with your funders' reporting mandates. Clear acknowledgement of funder support is an important consideration in funding evaluation and can increase your chances of securing funding in the future. We work closely with Crossref to make your research discoverable through the Funding Data search tool (http://search.crossref.org/funding).

Further information on how to acknowledge your funders can be found on our webpage (http://rsc.li/funding-info).

\section{What is Funding Data?}

Funding Data (http://www.crossref.org/fundingdata/) provides a reliable way to track the impact of the work that funders support. We collect funding information from our authors and match this information to funders listed in the Crossref Funder Registry. Once an article has been matched to its funders, it is discoverable through Crossref's search interface.

\section{PubMed Central}

Accurate funder information will also help us identify articles that are mandated to be deposited in PubMed Central (PMC) and deposit these on your behalf.

\section{Providing funder information}

We have combined the information you gave us on submission with the information in your acknowledgements. This will help ensure funding information is as complete as possible and matches funders listed in the Crossref Funder Registry. Please check that the funder names and grant numbers in the table are correct. This table will not be included in your final PDF but we will share the data with Crossref so that your article can be found via the Funding Data search tool.

\begin{tabular}{|l|l|l|}
\hline Funder name & Funder ID (for RSC use only) & Award/grant/contract number \\
\hline
\end{tabular}

If a funding organisation you included in your acknowledgements or on submission of your article is not currently listed in the registry it will not appear in the table above. We can only deposit data if funders are already listed in the Crossref Funder Registry, but we will pass all funding information on to Crossref so that additional funders can be included in future.

\section{Researcher information}

If any authors have ORCID or ResearcherID details that are not listed below, please provide these with your proof corrections.

Please check that the ORCID and ResearcherID details listed below have been assigned to the correct author. Authors should have their own unique ORCID iD and should not use another researcher's, as errors will delay publication.

Please also update your account on our online manuscript submission system to add your ORCID details, which will then be automatically included in all future submissions. See here for step-by-step instructions and more information on author identifiers.

\begin{tabular}{|l|l|l|l|}
\hline First (given) name(s) & Last (family) name(s) & ResearcherID & ORCID \\
\hline Colin C. & Seaton & & 0000-0003-4094-720X \\
\hline Rayan R. & Thomas & & \\
\hline Eman A. A. & Essifaow & & \\
\hline Elisa & Nauha & & \\
\hline
\end{tabular}




\begin{tabular}{|l|l|l|l|}
\hline Tasnim & Munshi & & \\
\hline $\operatorname{lan} \mathrm{J}$. & Scowen & & \\
\hline
\end{tabular}




\section{Queries for the attention of the authors}

Journal: CrystEngComm

Paper: c8ce00606g

Title: Structural motifs in salts of sulfathiazole: implications for design of salt forms in pharmaceuticals APIs

For your information: You can cite this article before you receive notification of the page numbers by using the following format: (authors), CrystEngComm, (year), DOI: 10.1039/c8ce00606g.

Editor's queries are marked on your proof like this Q1, Q2, etc. and for your convenience line numbers are indicated like this $5,10,15, \ldots$

Please ensure that all queries are answered when returning your proof corrections so that publication of your article is not delayed.

\begin{tabular}{|l|l|l|}
\hline $\begin{array}{c}\text { Query } \\
\text { Reference }\end{array}$ & \multicolumn{1}{|c|}{ Query Remarks } \\
\hline Q1 & $\begin{array}{l}\text { Please confirm that the spelling and format of all } \\
\text { author names is correct. Names will be indexed and } \\
\text { cited as shown on the proof, so these must be } \\
\text { correct. No late corrections can be made. }\end{array}$ & $\begin{array}{l}\text { Please check that the inserted CCDC numbers are } \\
\text { correct. }\end{array}$ \\
\hline Q2 & $\begin{array}{l}\text { Please check that the inserted Graphical Abstract } \\
\text { image and text are suitable. Please ensure that the } \\
\text { text fits between the two horizontal lines. }\end{array}$ & $\begin{array}{l}\text { P3 } \\
\text { rease note that a conflict of interest statement is } \\
\text { on Conflicts of interest (http://rsc.li/conflicts) and } \\
\text { provide a statement with your proof corrections. If no } \\
\text { conflicts exist, please state that "There are no } \\
\text { conflicts to declare". }\end{array}$ \\
\hline Q4
\end{tabular}




\title{
CrystEngComm
}

\section{Structural motifs in salts of sulfathiazole: implications for design of salt forms in pharmaceuticals APIs $\dagger$}

\author{
Colin C. Seaton, iD *a Rayan R. Thomas, ${ }^{a}$ Eman A. A. Essifaow, ${ }^{a}$ Elisa Nauha, \\ Tasnim Munshib and lan J. Scowen*b
}

Received 16th April 2018,

Accepted 29th May 2018

DOI: $10.1039 / \mathrm{c} 8 \mathrm{ce} 00606 \mathrm{~g}$

rsc.li/crystengcomm
The creation of salts is a frequently used approach for the modification of physicochemical properties of an active pharmaceutical ingredient. Despite the frequency of application, there has been little research into the structural-property relationships of the final material and the nature of the counterion present. This work reports on five new salts of sulfathiazole and compares the energetics of the intermolecular interactions with variation in the crystal packing motifs.

\section{Introduction}

Altering the physicochemical properties of drug materials through manipulation of their solid-state forms has attracted considerable attention. ${ }^{1}$ The creation of multi-component crystals (e.g. co-crystals, salts and solid solutions) is seen as a highly attractive and adaptable route for the modification of the physicochemical properties of active pharmaceutical ingredients (APIs) ${ }^{2-4}$ resulting from structural and electrostatic factors. Both salts and co-crystals feature a new crystal structures with defined intermolecular interactions between the two (or more) components, while a solid solution retains the parent crystal structure of one component with the second randomly distributed throughout the crystal lattice. Salts differ from cocrystals in that pairs of oppositely charged molecular species are present and in the case of organic salts, this often corresponds to a single proton transfer within the crystal.

The creation of such materials is now common and, in several cases, the new phases have been shown alterations of properties such as solubility, stability and process performance (e.g. tableting). ${ }^{5-10}$ Furthermore, utility of multicomponent approaches has been demonstrated in cases using co-crystallisation as a purification step. ${ }^{11,12}$ However, the design and selection of components and crystal forms is still often undertaken through trial and error or serendipitous study.

\footnotetext{
${ }^{a}$ School of Chemistry and Biosciences, University of Bradford, Bradford, BD7 1DP UK. E-mail: c.seaton@bradford.ac.uk

${ }^{b}$ School of Chemistry, Joseph Banks Laboratories, University of Lincoln, Lincoln, LN6 7TS, UK. E-mail: iscowen@lincoln.ac.uk

$\dagger$ Electronic supplementary information (ESI) available: Details of the crystal structure solution and refinement, crystal structure packing analysis of literature and crystallographic data in CIF or other electronic format see DOI: 10.1039/ c8ce00606g
}

Designing for a pre-defined change in physical properties, such as creating a new phase with a specific solubility, is still beyond the state of the art within the field. Many studies have focused on developing 'design' rules to predict how changes in molecular structure of the component can influence cocrystallisation. ${ }^{13-16}$ It has been shown that successful formation may be predicted by consideration of the interactions between the components, ${ }^{17}$ that the nature of the substituent groups can alter the ability to form co-crystals. ${ }^{14,18}$ In contrast comparable studies for salt formers are more unusual and while proton transfer can related to both chemical and crystallographic structure in certain systems, ${ }^{19}$ few studies investigating the interaction between molecular structures, intermolecular interactions and formation have been presented. Systematic examples altering the counterions have been reported for ephedrine, ${ }^{20-22}$ tyramine $^{23}$ gemfibrozil, flurbiprofen, ibuprofen and etodolac salts ${ }^{24}$ and studies into series of sulfonic acid salts have also emerged. ${ }^{25}$ Unlike cocrystals, salts feature an additional set of unidirectional electrostatic interactions between the charged species (both repulsive and attractive) in addition to the crystal packing directing interactions. Understanding the balance between the numerous potential interactions is required to design such functional materials. Alteration of the key interactions between the components within a salt by, for example, changing the nature of the counterion (and its ability to hydrogen bond, form common motifs and intervene in the hydrogen patterns of the analogous molecular systems) will directly influence the lattice energy of the final phase and so the physicochemical properties of the new phase. Given the nondirectional nature of electrostatic interactions, and their influence over long-ranges, investigating the relative importance of such interactions in the context of other intermolecular forces requires relatively sophisticated computational evaluations. 


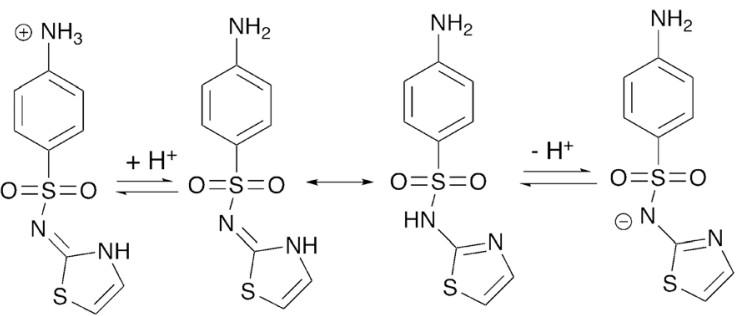

Fig. 1 Molecular structures of STZ showing tautomerism and potential salt forms.

Table 1 Previously published STZ salts with acids ${ }^{a}$

$\begin{array}{ll}\text { REFCODE } & \text { Chemical structure } \\ \text { BUWDUT } & \end{array}$

KUFWIT

\$ Cambridge structure database (CSD) version 5.37 with 3 updates was searched

UDAKOA

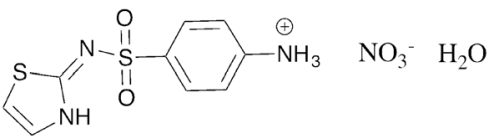

${ }^{a}$ Results from a CSD search as detailed before. Protonated and deprotonated forms of each tautomer were searched.

Such approaches offer significant potential for insight into the assembly of salt-forms. Recently computational studies have indicated that the central role of directing hydrogen bonding in the analysis and design of organic materials has been overemphasised ${ }^{26}$ and calculation of interaction energies between the molecular species is required to fully understand the assembly of the crystal structure.

Sulfathiazole (STZ) is well established as a studied model active pharmaceutical ingredient (API) and its five polymorphic forms have been extensively considered. ${ }^{27}$ There are a plethora of multi-component crystals formed including over one hundred solvates ${ }^{28}$ however, published crystal structures are only available for thirteen co-crystals (Table S2 $\dagger$ ) $\$$ The molecule can undergo tautomerism and capable of forming salts with either acids or bases (Fig. 1). Previous studies into STZ salts are also limited to four systems with STZ acting as a base and nine where it acts as an acid (Tables 1 and 2). This range of structural flexibility means that STZ offers an interesting material for further study to identify the role of using Conquest 1.18 for systems containing either tautomer. Only organic systems were included.

Table 2 Previously published STZ salts with bases ${ }^{a}$

BUHMOI

DOWPUC<smiles>NC(=[NH2+])c1ccccc1</smiles>

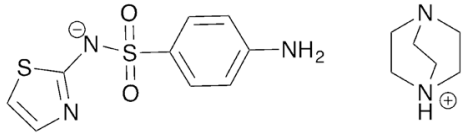

DOWQAJ

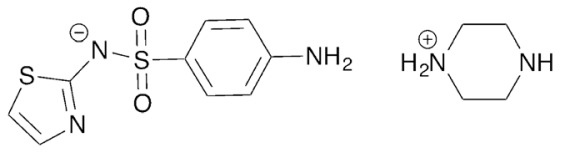

HSLSTZ

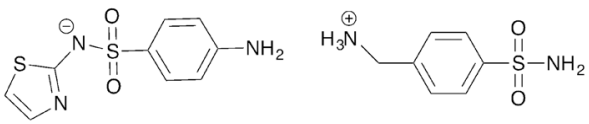

OHUWAR

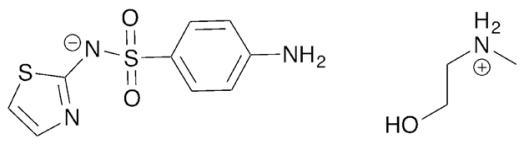

OHUWEV
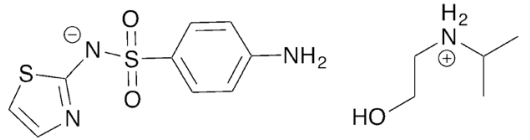

OHUWIZ deprotonated forms of each tautomer were searched.

different structural factors and intermolecular interactions on solid formation. To this end, salt formation between STZ and nitric acid (I), tetrafluoroboric acid (II), sulfuric acid (III), hydrochloric acid (IV), benzenesulfonic acid (V) and toluenesulfonic acid (VI) (Scheme 1) was investigated to identify how the crystal structure motifs are altered by variation of the components of the salt. The energetics of the new systems alongside those identified in the CSD were studied to identify<smiles>O=[N+]([O-])[O-]</smiles><smiles>F[B-](F)(F)F</smiles><smiles>O=S(=O)([O-])O</smiles><smiles>O=S(=O)(Cl)c1ccccc1</smiles>

(I)
(II)

(III)

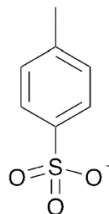

(VI)
Scheme 1 Chemical structures of counterions used in this study. 
the dominant interactions and how these potentially influence the lattice characteristics (energy and structure) of ionised components in these organic salts.

\section{Methodology}

\section{Experimental}

Crystallisation. Sulfathiazole salts were prepared by adding the appropriate acid $(1 \mathrm{mmol})$ to a solution of sulfathiazole $(1 \mathrm{mmol})$ in either methanol or acetone $\left(4 \mathrm{~cm}^{3}\right)$. The solutions were filtered to obtain clear solutions and then slow evaporation of the solvent was allowed to promote crystal growth. Single crystals suitable for crystal structure analysis were obtained for I, II, III, V and VI, while PXRD on the powders obtained for IV indicated a new crystal phase, successful growth of suitable crystal was not achieved for IV.

Single crystal structure determination. The crystallographic details for all systems are given in Table S1. $\dagger$ The data was collected on a Bruker X8 Apex II diffractometer using graphite monochromated Mo $\mathrm{K} \alpha$ radiation at $173 \mathrm{~K}$. The data was collected and reduced using Bruker SMART software. The structures of I, II and III were solved and refined using SHELXTL, whereas the structures of $\mathbf{V}$ and VI were solved and refined in Olex2 (ref. 29) using SHELXT and SHELXL. ${ }^{30}$ The structure of VI revealed the presence of a channel containing disordered solvent; this was modelled using squeeze methodology in Platon. ${ }^{31}$ The resulting structure files have been deposited with Cambridge Crystallographic Data Centre (CCDC 1499236-1499240).

\section{Computational}

Lattice energies. The hydrogen locations in all crystal structures were normalised and the lattice energies of resulting structures minimised using Forcite in the Materials Studio package. Given the wide range of atom types in the salts considered, a limited number of force fields were available for the energy calculations. Lattice energies were calculated using the Universal force field ${ }^{32,33}$ with atomic point charges derived for each molecule by fitting to the electrostatic potential calculated from a DFT calculation (TPSS-D3/ def2-TZVPPD) $)^{34-36}$ in the program orca, ${ }^{37}$ for all systems, while AA-CLP force field $^{38}$ was also used for selected systems.

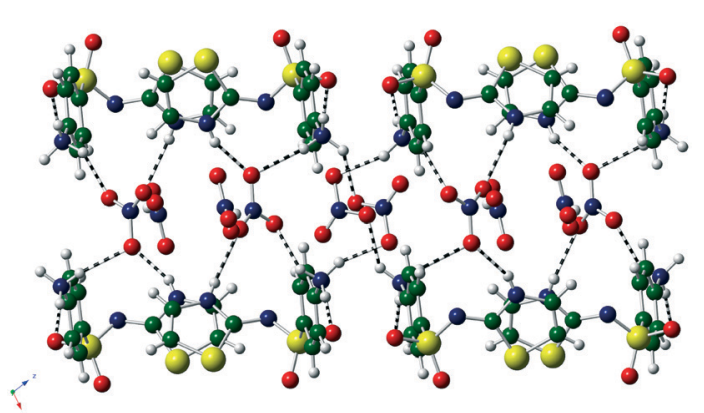

Fig. 2 Formation of bilayer structure in I between $\mathrm{STZH}^{+}$and $\mathrm{NO}_{3} /$ $\mathrm{HNO}_{3}$ ions.

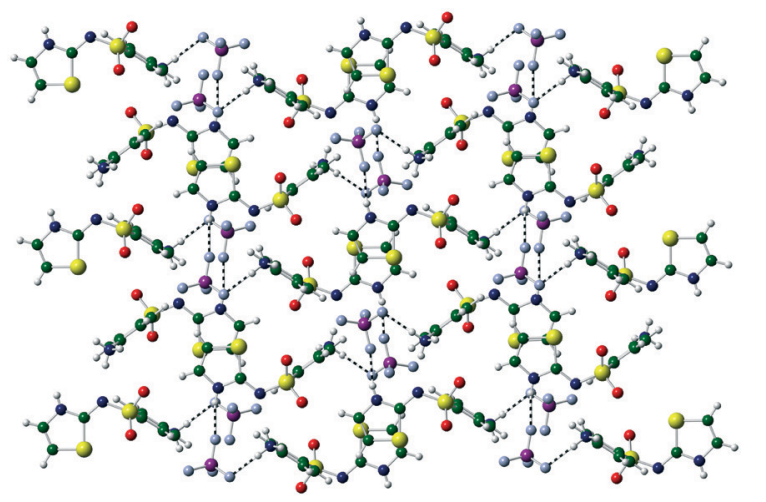

1

Fig. 3 Formation of a 2-D sheet in II through $\mathrm{NH} \cdots \mathrm{N}$ and $\mathrm{NH} \cdots \mathrm{F}$ bonds.

In this case, the crystal structures were optimised by downhill simplex method with fixed unit cell parameters. For III, V and BUWDUT, the disordered crystal structures were converted to ordered models in lower symmetries. In the case of III and V, the unit cells were initially reduced to $P 1$ symmetry, half of the disordered components were removed and additional symmetry identified by ADDSYM program in Platon to give a $Z^{\prime}=1$ structure in $P 2_{1} / c$ (III) and a $Z^{\prime}=2$ structure in $\operatorname{Pna}_{1}$ (V). For BUWDUT, half the disordered components were removed and the symmetry reduced to $P \overline{1}$.

Molecular clusters. Dimers and higher molecular clusters were extracted from the relevant crystal structure and the hydrogen atom locations optimised in the program orca (TPSS$\mathrm{D} 3 / \mathrm{TZV}(\mathrm{d})$ (main group) TZV (hydrogen)). ${ }^{39,40}$ The binding energies were then calculated at the TPSS-D3/def2-TZVPPD level of theory with the basis set superposition error corrected for by the counterpoise method of Boys and Bernardi. ${ }^{41}$

\section{Results and discussion}

Crystal structure analysis

Salt $\mathbf{I}$ is shown to be a hydrogen nitrate salt $\left(\mathrm{NO}_{3} / \mathrm{HNO}_{3}\right)$. The $\mathrm{STZH}^{+}$molecules link into a 1-D chain with a $\mathrm{NO}_{3} / \mathrm{HNO}_{3}$ pair bridging the two chains through $\mathrm{NH} \cdots \mathrm{O}$ bonds to forming a bilayer structure (Fig. 2). These 2-D layers then link to form the final 3-D structure through weaker $\mathrm{CH} \cdots \mathrm{O}=\mathrm{S}$ interactions.

Salt II forms a 1:1 salt with $\mathrm{BF}_{4}^{-}$, which produces a 1-D chain between $\mathrm{STZH}^{+}$cations through $\mathrm{N}-\mathrm{H} \cdots \mathrm{N}$ hydrogen bonds, with the $\mathrm{BF}_{4}{ }^{-}$anion bonding through $\mathrm{N}-\mathrm{H} \cdots \mathrm{F}$ interactions to form a 2-D sheet structure (Fig. 3). The final 3-D structure is formed through $\mathrm{NH} \cdots \mathrm{O}=\mathrm{S}$ hydrogen bonds.

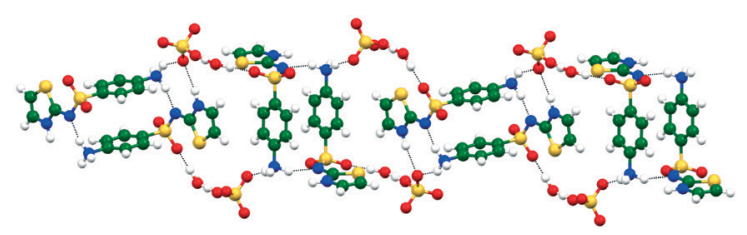

Fig. 4 Formation of a 1-D chain between $\mathrm{STZ} / \mathrm{HSO}_{4}{ }^{-} / \mathrm{OH}^{-}$groups in III. 
The crystal structure of III indicates that two molecules of STZ, a single sulfate ion and an isolated oxygen atom present in the asymmetric cell. However, the disorder in the structure makes it hard to clearly identify all the hydrogen atoms and resolve the system as either $\mathrm{HSO}_{4}{ }^{-} / \mathrm{OH}^{-}$or $\mathrm{SO}_{4}{ }^{2-} / \mathrm{H}_{2} \mathrm{O}$. The $\mathrm{S}-\mathrm{O}$ bond lengths in the sulfate group are characteristic of a $\mathrm{HSO}_{4}{ }^{-}$anion (three $\sim 1.45 \AA$ and one $\sim 1.55 \AA$ ). The distance from the isolated oxygen to the oxygen in the sulfate group is very short $(1.8 \AA)$ and so a central shared hydrogen present between the groups is possible. The crystal structure of III is isostructural to that of BUWDUT. The STZ cations hydrogen bond into a dimer through ${ }^{+} \mathrm{NH} \cdots \mathrm{N}=$ hydrogen bonds, which then form a 1-D chain through $\mathrm{NH} \cdots \mathrm{O}$ hydrogen bonds with the $\mathrm{HSO}_{4}{ }^{-} / \mathrm{OH}^{-}$cluster (Fig. 4). The final 3-D structure is constructed through the interlinking of these chains.

Salt $\mathbf{V}$ formed with benzenesulfonate has a 1:1 composition and the crystal structure displays an orientation disorder in the aromatic component with a 50:50\% split. The two components are hydrogen bonded together through $\mathrm{NH} \cdots \mathrm{O}=\mathrm{S}$ hydrogen bonds to form two ring motifs, one a $\mathrm{R}_{4}^{4}(12)$ motif formed by two benzenesulfonate $\mathrm{SO}_{3}$ groups bridging two $\mathrm{NH}_{3}{ }^{+}$group on STZ (Fig. 5a), while the second is a $\mathrm{R}_{4}^{4}(28)$ motif which binds four molecules through $\mathrm{N}_{\text {ring }}{ }^{-}$ $\mathrm{H} \cdots \mathrm{O}=\mathrm{S}$ and $\mathrm{NH}_{3}{ }^{+} \cdots \mathrm{O}=\mathrm{S}$ bonds (Fig. 5b). The combination of these motifs form a 2-D sheet structure in the crystal, which are packed into the final 3-D structure through $\mathrm{CH} \cdots \mathrm{O}=\mathrm{S}$ interactions.

Crystal structure determination of VI confirmed that STZ had undergone an acid catalysed aldol reaction with the acetone solvent (Scheme 2). The resulting product forms a salt with the toluenesulfonic acid. Attempts to crystallise from other solvents resulted in poor quality crystals and attempts

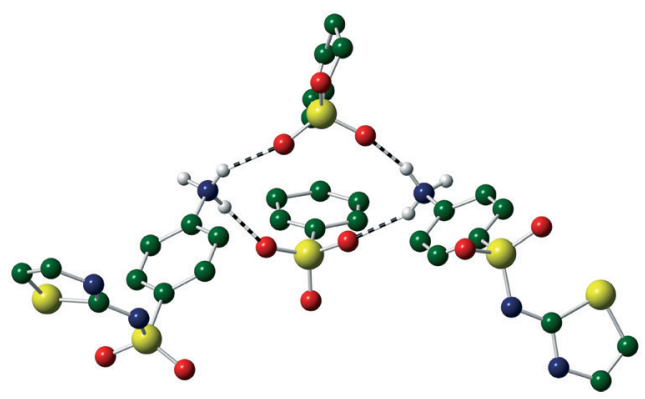

Fig. 5 Formation of tetramers in the crystal structure of $V$, (a) $R_{4}^{4}(12)$ motif and (b) $R_{4}^{4}(28)$ motif. Only one component of disordered benzenesulfonate counterion is shown and selected hydrogens removed for clarity.

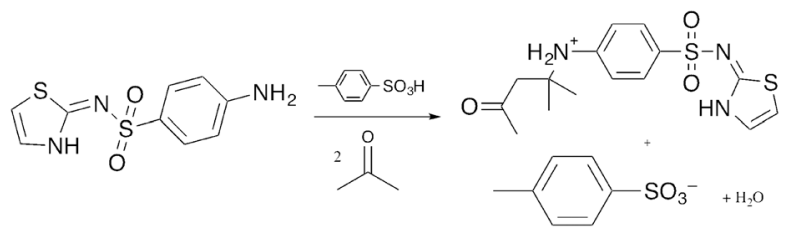

1

Scheme 2 Formation of aldol product (VI) with sulfathiazole and toluenesulfonic acid.

to determine a structure for STZ with toluenesulfonate were unsuccessful. Strong ${ }^{+} \mathrm{NH} \cdot{ }^{-} \mathrm{O}=\mathrm{S}$ hydrogen bonds between the two components of the salt, forms a 1-D channel which is filled with disordered solvent (Fig. 6). The channel void space is calculated to be $277 \AA^{3}$ (10\% of unit cell volume) and runs through the entire crystal structure along the $b$-axis. These channels are linked through weaker $\mathrm{CH} \cdots \mathrm{O}$ bonds to construct the final crystal structure.

\section{Comparison of crystal structures}

Analysis of the crystal packing of the structures present in the CSD is given in the ESI. + While all the known STZ polymorphs form dimers between the STZ molecules, dimer formation only occurs in three salts (BUWDUT, KUFWIT and III) that display different hydrogen bonding to each other and the polymorphs. While a repulsion between the positively charged STZ ions would be expected, the relative isolation of the charged species at one end of the relative large component the sum of other interactions may be larger enough to overcome the repulsion. Thus, the interaction energies were quantified for the various crystals and molecular components.

\section{Computational studies}

Lattice energies for the STZ salts were calculated using two force fields (Table 3 ) that give different ordering of the crystal structures. However, in both cases the lowest energy systems

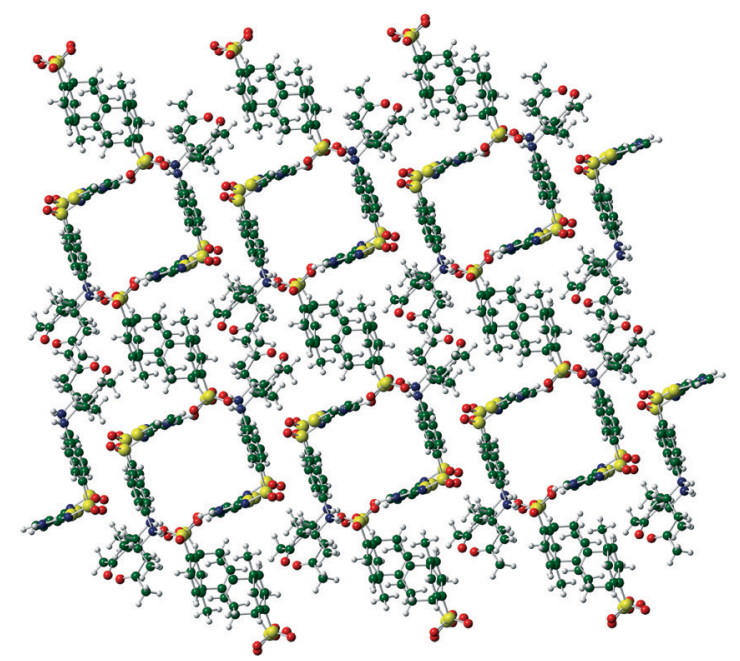

Fig. 6 Formation of channel structure in VI. 
Table 3 Calculated lattice energies of STZ salts (sorted by AA-CLP energies)

\begin{tabular}{lll}
\hline System & Universal force field lattice energy $\left(\mathrm{kJ} \mathrm{mol}^{-1}\right)$ & AA-CLP lattice energy $\left(\mathrm{kJ} \mathrm{mol}{ }^{-1}\right)$ \\
\hline BUWDUT $\left(\mathrm{SiF}_{6}{ }^{2-}\right)$ & -917.57 & -739.73 \\
III $\left(\mathrm{SO}_{4}{ }^{2-} / \mathrm{H}_{2} \mathrm{O}\right)$ & -765.86 & -523.15 \\
III $\left(\mathrm{HSO}_{4}^{-} / \mathrm{OH}^{-}\right)$ & -444.8 & -484.25 \\
V (benzenesulfonate) & -232.23 & -417.65 \\
I $\left(\mathrm{NO}_{3}^{-} / \mathrm{HNO}_{3}\right)$ & -165.03 & -403.11 \\
KUFWIT $(2,4$-dinitrobenzoate/2,4-dinitrobenzoic acid) & -544.1 & -288.562 \\
LOFMAW (hydrogen oxalate) & -579.1 & -254.372 \\
LOFMAW01 (hydrogen oxalate) & -517.15 & -239.478 \\
UDAKOA $\left(\mathrm{NO}_{3}{ }^{-} / \mathrm{H}_{2} \mathrm{O}\right)$ & -209.58 & -209.97 \\
II $\left(\mathrm{BF}_{4}^{-}\right)$ & -313.69 & -184.91
\end{tabular}

Table 4 Binding energies of key motifs in STZ salts crystal structures

\begin{tabular}{|c|c|c|c|}
\hline System & $\mathrm{STZH}^{+} /$anion energy $\left(\mathrm{kJ} \mathrm{mol}^{-1}\right)$ & $\mathrm{STZH}^{+} / \mathrm{STZH}^{+}$energy $\left(\mathrm{kJ} \mathrm{mol}^{-1}\right)$ & Anion/anion energy $\left(\mathrm{kJ} \mathrm{mol}^{-1}\right)$ \\
\hline BUWDUT $\left(\mathrm{SiF}_{6}^{2-}\right)$ & -700.17 & 45.72 & 964.05 \\
\hline LOFMAW01 (hydrogen oxalate) & -462.85 & 154.25 & 156.30 \\
\hline UDAKOA $\left(\mathrm{NO}_{3}^{-} / \mathrm{H}_{2} \mathrm{O}\right)$ & -434.76 & 121.34 & 252.72 \\
\hline $\mathrm{II}\left(\mathrm{BF}_{4}^{-}\right)$ & -430.83 & 110.98 & 313.56 \\
\hline $\mathrm{I}\left(\mathrm{NO}_{3}^{-} / \mathrm{HNO}_{3}\right)$ & -362.81 & 115.28 & 343.08 \\
\hline V (benzenesulfonate) & -289.98 & 107.22 & 422.25 \\
\hline LOFMAW (hydrogen oxalate) & -250.80 & 125.82 & 221.86 \\
\hline KUFWIT (2,4-dinitrobenzoate) & -203.88 & 5.91 & 229.05 \\
\hline III $\left(\mathrm{HSO}_{4} / \mathrm{H}_{2} \mathrm{O}\right)^{a}$ & -94.37 & 57.86 & 939.97 \\
\hline
\end{tabular}

${ }^{a}$ After hydrogen position optimisation, the cation $\cdots$ anion system had rearranged to give a trimer with a $\mathrm{HSO}_{4}, \mathrm{H}_{2} \mathrm{O}$ and a neutral STZ. Anion pairs calculated for $\mathrm{SO}_{4}{ }^{2-}$ system.

are those systems with the largest charge on a single counterion $\left(\mathrm{SiF}_{6}{ }^{2-}\right.$ and $\left.\mathrm{SO}_{4}{ }^{2-}\right)$. Alteration of the hydrogen location for III (from $\mathrm{SO}_{4}{ }^{2-}$ to $\mathrm{HSO}_{4}{ }^{-}$) alters the absolute energy of the system but not the relative position in either list. Both these structures are isostructural and so geometrical and electrostatic interactions appear to be dominant in this case. The systems with specific hydrogen bonds between the components have lower lattice energies suggesting that complementary design of hydrogen bonding with electrostatic and geometric factors could be a key factor in the creation of high stability phases.

\section{Molecular dimers}

The energies of closest pairs of $\mathrm{STZH}^{+} / \mathrm{STZH}^{+}, \mathrm{STZH}^{+} /$anion and anion/anion ions from each crystal structure were calculated for the geometry in the crystal structure (Table 4, nates the energetics, with attractive forces between the anion and cation and repulsive forces in the cation/cation and anion/anion pairs. Dimers between $\mathrm{STZH}^{+}$ions are present in III, BUWDUT and KUFWIT. In III and BUWDUT are linked through two $\mathrm{NH} \cdots \mathrm{N}$ hydrogen bonds, while KUFWIT utilises two $\mathrm{NH} \cdots \mathrm{O}=\mathrm{S}$ bonds. In both cases the energy gained by the interactions offsets the repulsive energy of the electrostatic interaction within the dimer. However, during the hydrogen location optimisation for III cation/anion pair, significant rearrangement of the hydrogen atoms took place resulting in ergy. The remaining systems have a single hydrogen bond between the $\mathrm{STZH}^{+}$ions forming a 1-D chain motif in each case; this does not shield repulsive interaction as effectively. The difference in binding energy for the two polymorphs of the oxalate appears to be driven by the different conformations of the oxalate anion. In form I, an intramolecular hydrogen bond stabilises that form by $41.33 \mathrm{~kJ} \mathrm{~mol}^{-1}$.

The polymorphs of pure STZ display dimers in forms I-IV and a tetramer in form $\mathrm{V}$. The hydrogen bonding in form I differs from forms II-IV as it contains a $R_{2}^{2}(8)$ motif formed by $\mathrm{NH}^{\cdots} \mathrm{N}$ bonds, while the other, has a mix of $\mathrm{NH}^{\cdots} \mathrm{N}$ and

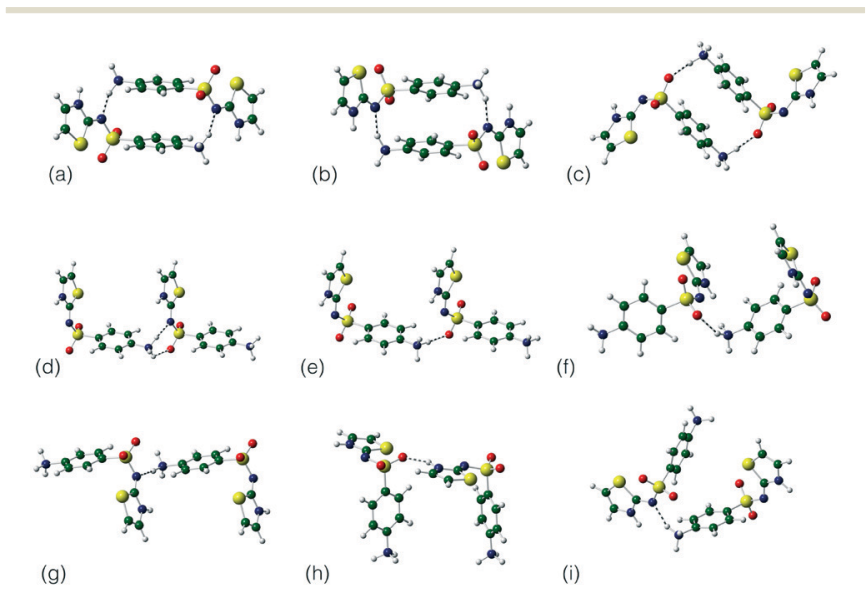

Fig. 7 Hydrogen position optimised $\mathrm{STZH}^{+} / \mathrm{STZ}^{+}$dimers in (a) BUWDUT, (b) III, (c) KUFWIT (d) V, (e) I, (f) UDAKOA, (g) LOFMAW, (h) LOFMAW01 and (i) II. a neutral STZ molecule, which gives a significantly lower en- 

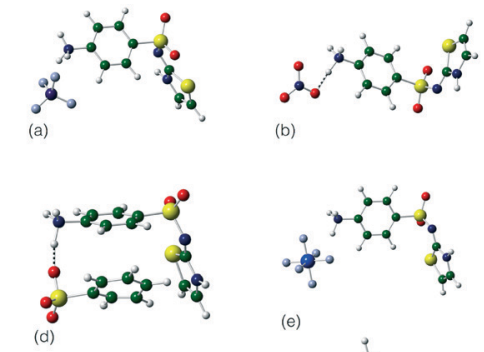

(e)
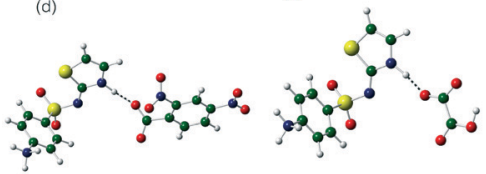

(h)
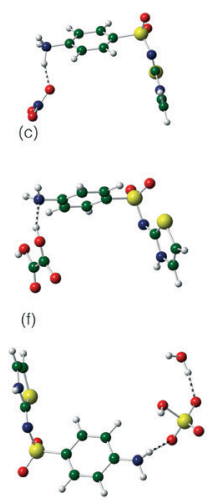

(i)
Fig. 8 Hydrogen position optimised anion/STZ dimers in (a) II, (b) UDAKOA, (c) I, (d) V, (e) BUWDUT, (f) LOFMAW01, (g) KUFWIT, (h) LOFMAW and (i) III.

$\mathrm{NH}^{\cdots} \mathrm{O}=\mathrm{S}$ bonds (Fig. 10). The mixed H-bond motif is the lowest energy (Table 5), however it is present in the stable phases of STZ and is not similar to the motifs present in the salts determined. Importantly, these H-bonded motifs all correspond with attractive STZ $\cdots \mathrm{STZ}$ interaction in the lattice.

As expected, the STZ $\cdots$ STZ interactions in the salts change to repulsive in the crystal lattice (Table 2). Three distinct groupings arise from considering the repulsions: (i) $<50 \mathrm{~kJ}$ $\mathrm{mol}^{-1}$ [III, BEWDUT and KUFWIT], (ii) 100-125 kJ mol${ }^{-1}$ [I, II, $\mathrm{V}$, UDAKOA, LOFMAW], (iii) $>150 \mathrm{~kJ} \mathrm{~mol}^{-1}$ [LOFMAW01]. It might be helpful in this context to view the salts as arrays of repulsive cations, whose repulsive interactions are mediated by the counterions. Broadly, it appears that interactions between the anion centres and the protonated amine (the centre of cationic charge), exerts a considerable influence in mediating the STZ $\cdots$ STZ repulsion. Intriguingly, these correlate with the relative dispositions of the protonated aniline centre of adjacent $\mathrm{STZH}^{+}$units in the crystal structure and the numbers of anions in the local vicinity: for grouping (i), the $\mathrm{STZH}^{+}$systems are arranged in a head-to-tail orientation an each have two anions in close contact with each anilinyl $\left(-\mathrm{NH}_{3}{ }^{+}\right)$centre the remaining interaction to $\mathrm{S}=\mathrm{O}$ and/or $\mathrm{S}-\mathrm{N}$ of an adjacent

Fig. 9 Hydrogen position optimised anion/anion pairs in (a) LOFMAW, (b) LOFMAW01, (c) KUFWIT, (d) V, (e) UDAKOA, (f) I, (g) II, (h) BUWDUT and (i) III.

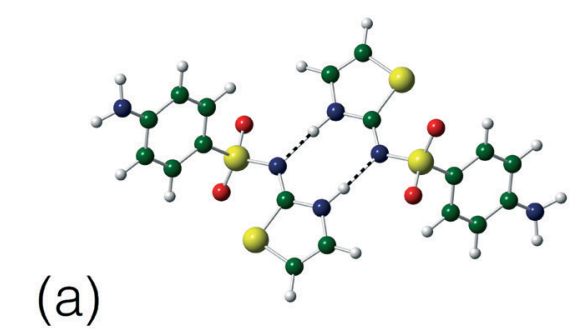

1

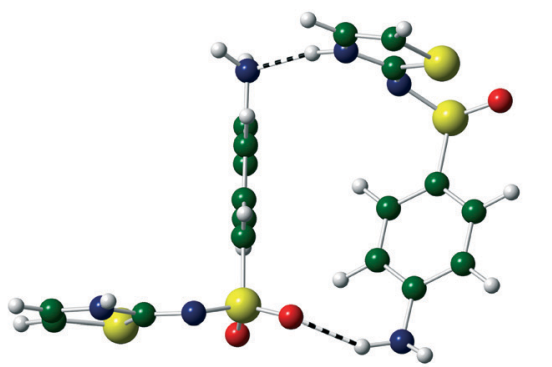

10

(b)

15

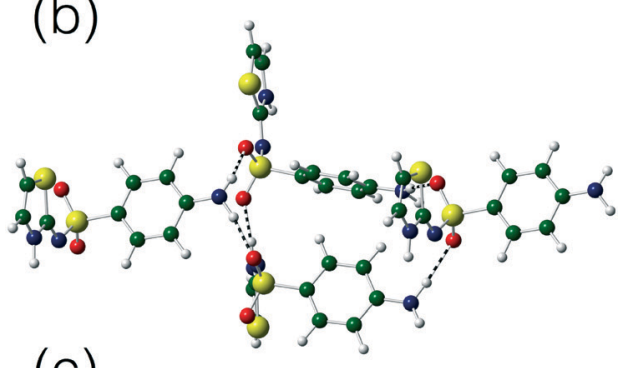

20

25

Fig. 10 Comparison of the molecular motifs in (a) form I, (b) forms IIIV and (c) form V STZ.

$\mathrm{STZH}^{+}$. For group (ii), the layered structures have a $\mathrm{STZH}^{+}$system in a head-to-tail orientation, but only one close contact with the counterion is observed (again remaining interactions at the $\mathrm{NH}_{3}{ }^{+}$arise from $\mathrm{S}=\mathrm{O} / \mathrm{S}-\mathrm{N}$ or $\mathrm{HN}$ ). For (iii), the LOFMAW01 outlier has close contacts to an oxH $\cdots$ oxH centrosymmetric dimer that brings the adjacent $\mathrm{STZH}^{+}$molecules together in a 'head to-head' orientation. Overall, it appears that increasing the number of anions surrounding the cation centre and their charge density effectively screens the repulsion between adjacent cations. Clearly this repulsion is maximised in the 'head-to-head' configuration. Similarly, the converse also appears to be true. Bringing charge dense anion centres into close proximity (III and BUWDUT), causes very large relative anion anion repulsions in excess of $600 \mathrm{~kJ} \mathrm{~mol}^{-1}$ compared to the more distal anions. While such 'chargebalance' concepts may prove valuable in unpicking the relative influences, it is the interplay of the relative cation-anion attractions, and cation-cation/anion-anion repulsions that

Table 5 Energies for STZ polymorphs key motifs

\begin{tabular}{lll}
\hline Polymorph & $\begin{array}{l}\mathrm{STZ} \cdots \mathrm{STZ} \text { energy } \\
\left(\mathrm{kJ} \mathrm{mol}^{-1}\right)\end{array}$ & $\begin{array}{l}\text { Energy per molecule } \\
\left(\mathrm{kJ} \mathrm{mol}^{-1}\right)\end{array}$ \\
\hline Form I dimer & -109.42 & -54.71 \\
Form II/III/IV dimer & -41.49 & -20.75 \\
Form V tetramer & -143.29 & -35.82
\end{tabular}

30

35

40

45 
dominate in the overall determination of the lattice energy. Importantly, H-bonded motifs may considerably have less influence in ionised systems in the solid state.

\section{Conclusions}

These studies have established an important approach to understanding the relative importance of intermolecular interactions in salts of pharmaceutical products, through a combination of systematic experimentation (complimenting database structures) and computational analysis of the lattice energies of the resulting crystal structures. It appears from this study that converting molecular species with potential to form diverse hydrogen bonding motifs in the solid to their analogous salt forms switches the intermolecular interaction from attraction to overall repulsion. Furthermore, the mediation of repulsion between charged centres with judicious choice of anion to 'screen' the repulsions between adjacent molecules, offers a route to influence lattice energy and hence the crystal packing of pharmaceutical ingredients.

\section{Conflicts of interest}

\section{Notes and references}

1 N. Blagden, M. de Matas, P. T. Gavan and P. York, Adv. Drug Delivery Rev., 2007, 59, 617-630.

2 I. Miroshnyk, S. Mirza and N. Sandlert, Expert Opin. Drug Delivery, 2009, 6, 333-341.

3 R. Thakuria, A. Delori, W. Jones, M. P. Lipert, L. Roy and N. Rodriguez-Hornedo, Int. J. Pharm., 2013, 453, 101-125.

4 Ö. Almarsson and M. J. Zaworotko, Chem. Commun., 2004, 1889-1896.

5 A. V. Trask, W. D. S. Motherwell and W. Jones, Cryst. Growth Des., 2005, 5, 1013-1021.

6 S. Karki, T. Friščić, L. Fábián, P. R. Laity, G. M. Day and W. Jones, Adv. Mater., 2009, 21, 3905-3909.

7 H. D. Williams, N. L. Trevaskis, S. A. Charman, R. M. Shanker, W. N. Charman, C. W. Pouton and C. J. H. Porter, Pharmacol. Rev., 2012, 65, 315-499.

8 D. R. Weyna, M. L. Cheney, N. Shan, M. Hanna, M. J. Zaworotko, V. Sava, S. Song and J. R. Sanchez-Ramos, Mol. Pharmaceutics, 2012, 9, 2094-2102.

9 C. B. Aakeröy, Acta Crystallogr., Sect. B: Struct. Sci., Cryst. Eng. Mater., 2015, 1-5.

10 G. Bolla and A. Nangia, Chem. Commun., 2016, 52, 8342-8360.

11 A. Delori, T. Friščić and W. Jones, CrystEngComm, 2012, 14, 2350.

12 P. Billot, P. Hosek and M.-A. Perrin, Org. Process Res. Dev., 2013, 17, 505-511.
13 G. R. Desiraju, J. Am. Chem. Soc., 2013, 135, 9952-9967.

14 C. C. Seaton, CrystEngComm, 2011, 13, 6583-6595.

15 C. B. Aakeröy and D. J. Salmon, CrystEngComm, 2005, 7, 439-448.

16 T. Friščić and W. Jones, Cryst. Growth Des., 2009, 9, 1621-1637.

17 D. Musumeci, C. A. Hunter, R. Prohens, S. Scuderi and J. F. McCabe, Chem. Sci., 2011, 2, 883-890.

18 C. C. Seaton, K. Chadwick, G. Sadiq, K. Guo and R. J. Davey, Cryst. Growth Des., 2010, 10, 726-733.

19 C. C. Seaton, CrystEngComm, 2014, 16, 5878-5886.

20 E. A. Collier, R. J. Davey, S. N. Black and R. J. Roberts, Acta Crystallogr., Sect. B: Struct. Sci., 2006, 62, 498-505.

21 S. N. Black, E. A. Collier, R. J. Davey and R. J. Roberts, J. Pharm. Sci., 2007, 96, 1053-1068.

22 C. L. Cooke, R. J. Davey, S. N. Black, C. Muryn and R. G. Pritchard, Cryst. Growth Des., 2010, 10, 5270-5278.

23 N. E. B. Briggs, A. R. Kennedy and C. A. Morrison, Acta Crystallogr., Sect. B: Struct. Sci., 2012, 68, 453-464.

24 S. E. David, P. Timmins and B. R. Conway, Drug Dev. Ind. Pharm., 2012, 38, 93-103.

25 D. P. Elder, E. Delaney, A. Teasdale, S. Eyley, V. D. Reif, K. Jacq, K. L. Facchine, R. S. Oestrich, P. Sandra and F. David, J. Pharm. Sci., 2010, 99, 2948-2961.

26 A. Gavezzotti, CrystEngComm, 2013, 15, 4027-4035.

27 A. Munroe, Å. C. Rasmuson, B. K. Hodnett and D. M. Croker, Cryst. Growth Des., 2012, 12, 2825-2835.

28 A. L. Bingham, D. S. Hughes, M. B. Hursthouse, R. W. Lancaster, S. Tavener and T. L. Threlfall, Chem. Commun., 2001, 603-604.

29 O. V. Dolomanov, L. J. Bourhis, R. J. Gildea, J. A. K. Howard and H. Puschmann, J. Appl. Crystallogr., 2009, 42, 339-341.

30 G. M. Sheldrick, Acta Crystallogr., Sect. A: Found. Crystallogr., 2008, 64, 112-122.

31 A. L. Spek, Acta Crystallogr., Sect. C: Struct. Chem., 2015, 71, 9-18.

32 C. Casewit, K. Colwell and A. Rappe, J. Am. Chem. Soc., 1992, 114, 10035-10046.

33 C. Casewit, K. Colwell and A. Rappe, J. Am. Chem. Soc., 1992, 114, 10046-10053.

34 D. Rappoport and F. Furche, J. Chem. Phys., 2010, 133, 134105.

35 S. Grimme, J. Antony, S. Ehrlich and H. Krieg, J. Chem. Phys., 2010, 132, 154104.

36 S. Grimme, S. Ehrlich and L. Goerigk, J. Comput. Chem., 2011, 32, 1456-1465.

37 F. Neese, WIREs Comput. Mol. Sci., 2012, 2, 73-78.

38 A. Gavezzotti, New J. Chem., 2011, 35, 1360-1368.

39 A. Schaefer, H. Horn and R. Ahlrichs, J. Chem. Phys., 1992, 97, 2571.

40 F. Weigend and R. Ahlrichs, Phys. Chem. Chem. Phys., 2005, 7, 3297.

41 S. Boys and F. Bernardi, Mol. Phys., 1970, 19, 553-566.
1

5 